\title{
On the variable nature of head final effects in German and English
}

\author{
An interface account
}

\author{
Roland Hinterhölzl \\ University Ca' Foscari of Venice
}

\begin{abstract}
The paper investigates head final effects (HF-effects) in German and English and argues that the syntactic configuration that underlies them gives rise to three different types of violations in the interfaces. It is shown that HF-effects are either morphological or prosodic in nature. A diagnostics - morphological versus syntactic displacement - is established that allows to connect HF-effects to their relevant interface conditions. The prosodic conditions on word order are then argued to be twofold: they involve a condition on heavy constituents, on the one hand, and a condition on the mapping of syntactic constituents onto prosodic constituents respecting the Strict Layer Hypothesis, on the other hand. Finally, I argue that a pure syntactic condition, like the Final-over-Final Constraint proposed by Biberauer, Holmberg and Roberts (2007, 2014, to appear) is inedaquate to account for the variable nature of HF-effects.
\end{abstract}

\section{Introduction}

The paper investigates the presence/absence of head final effects (HF-effects) in the verbal and nominal domain in English and German. I will show that HF-effects in the two languages despite of their first appearance vary in their nature and require different explanations. In particular, I will argue that HF-effects in German and English do not represent a uniform phenomenon, even though they are based on the same syntactic configuration, but result from three different types of constraints that are operative in the syntax-prosody and in the syntax-morphology interface, and are given in (1) and (2).

(1) Conditions operating in the syntax-prosody interface

a. Weight condition: In a weight-sensitive phase, a specifier that constitutes a heavy syntactic phrase must be mapped onto a strong branch in prosodic structure 
b. Phrasing condition: The prosodic structure ((A (B)) C ) cannot be mapped onto a flat prosodic structure respecting the SLH, unless $\mathrm{C}$ is an affix or a free clitic

(2) Condition operating in the interface between syntax and morphology Adjacency condition: A phrasal affix is fused with its selected stem at MF under strict adjacency

HF-effects appear in the sentential domain in English. Adjuncts that can occur between the subject and the vP obey restrictions which are absent in OV-languages (cf. Haider $2000,2013,2015)$, as is illustrated by the contrasts in (3). HF-effects also appear in the nominal domain in both English and German, as is illustrated in (4). ${ }^{1}$

(3) a. John (more) often (*than Peter) read the book

b. John (very) carefully read the book

c. ${ }^{\star} J o h n$ with care read the book

d. Hans hat öfter (als der Peter) das Buch gelesen

John has more-often (than Peter) the book read

e. Hans hat das Buch (sehr) sorgfältig gelesen

John has the book (very) carefully read

f. Hans hat das Buch mit großer Sorgfalt gelesen John has the book with great care read

(4) a. a [AP proud] man

b. *a [AP proud [of his children] ] man

c. *ein [stolzer auf seine Kinder] Mann a proud of his children man

d. weil er [stolz auf seine Kinder] ist since he proud of his children is

What the data in (3) and (4) show is that the head of the adjunct must not have material to its right in head-initial structures, while no such restriction seems to apply in head final structures (cf. the minimal contrast in (4cd) in German). The contrast in (4ab) was first discussed by Emonds (1976) and Williams (1982). Williams (1982) proposed a condition that requires that the head of a prenominal modifier be adjacent to the (modified) noun. A generalized version of this condition that also captures the data in (3) is given in (5). Note that the traditional term pre-modifier in (5) is to be identified with a left-hand adjunct in modern terminology.

(5) Generalized Head Final Filter (HFF):

A pre-modifier must be head final

1. To the best of my knowledge, Haider $(1997,2000)$ first pointed out the connection between the restrictions on preverbal adverbials and prenominal modifiers, using the term edge effect. 
In this paper, I will argue that (5) cannot be maintained and needs to be replaced with the condition in (1a). Furthermore, I will take a closer look at HF-effects in the nominal domain in English and German and argue that while the English facts call for an analysis along the lines of (1a), the German facts are different and require an analysis that makes crucial use of the interface condition in (2). Then, I will investigate HF-effects in the vP-domain in German and show that these effects can neither be captured by condition (1a) nor by condition (2), but follow from general constraints on the formation of prosodic structures, and propose the condition in (1b). Finally, I will compare this interface account with a prominent new syntactic account of HFeffects, as proposed by Biberauer, Holmberg and Roberts (2010), the much-discussed Final-over-Final Constraint.

\section{The HFF as a syntactic condition}

While the HFF covers a great number of empirical facts (cf. Escribano 2009) and thus constitutes a valid empirical generalization, its status as a genuine syntactic condition is problematic for the following reasons.

First note that the HFF does not apply to subjects (that is, to the specifier of T) as in (6a), intonationally detached DP and PP frames (cf. 6b), which are traditionally analysed as adjuncts to CP/IP, and specifiers of functional heads in the C-domain (cf. 6c). This raises the question of why the condition should apply to adjuncts in the I-domain but not to adjuncts in the C-domain and furthermore, why it should apply to adjuncts but not to specifiers in the I-domain.

(6) a. [Students [of linguistics]] read Chomsky a lot

b. [On [Tuesday evening]] I will take out Mary for dinner

c. [In [which city]] did John meet Mary?

Secondly note that in Cinque's (1999) approach to modification, the HFF cannot be stated anymore as a genuine syntactic generalization that is based on the specific syntactic configuration of adjunction. If we get rid of adjunction, a problem arises for the statement of the HFF, since specifiers of functional projections are generally not subject to (5), as we have seen above.

Thirdly note that within current minimalist theory, the HFF is best treated as a bare output condition at the PF interface, since order and adjacency are taken to be irrelevant to narrow syntax. On the other hand, it is clear that the condition, as it is stated in (5), cannot be a genuine PF-constraint either, since the structural difference between specifiers and modifiers is no longer visible at PF. Therefore, I conclude that the HFF is in need of a deeper explanation. 
Alternatively, I will argue that the HF-effects in the verbal and nominal domain in English can be reduced to a metrical condition on a phase-based mapping between syntax and prosody that requires heavy syntactic phrases to occupy a dominant position in prosodic structure. HF-effects in English disappear, if the adjunct is epenthetic, constituting a separate intonational domain, as is indicated by the comma intonation in (7bc). Note that (7c) involves an elliptical construction with a clear prosodic boundary between negation and verb (as is indicated by the stress on the negation).

(7) a. ${ }^{\star} J o h n$ more often than Peter visited Mary

b. John, more often than Peter, visited Mary

c. John, more often than not, visited Mary

The observation that HF-effects are ameliorated if adjunct and verb are mapped into separate intonational phrases clearly speaks in favor of a condition that applies in the formation of prosodic constituents. Thus, I will discuss what is generally assumed about the mapping between syntactic structure and prosodic structure and propose a metrical approach to the interface in which the condition in (1) is embedded.

\section{On the mapping between syntactic and prosodic structure}

In the present paper, I will adopt a prominence-based approach to the mapping between syntactic structure and prosodic structure (cf. Halle \& Vergnaud 1987, Ladd 1994). This approach assumes that accents are assigned on the basis of prosodic constituents and the prominence relations among them, where both the prosodic constituents and their prominence relations in turn are derived from syntactic structure.

Note, however, that accent placement is not only dependent on syntactic structure in intonational languges, but is also crucially determined by information structure, that is, the focus-background articulation of the sentence in a particular context. That is why most researchers favour an accent-first based approach to the mapping between syntactic and prosodic structure (cf. Gussenhoven 1983, Uhmann 1991, Selkirk 1995).

The core of these accounts consists in focus projection rules (Selkirk 1995) which serve to derive the focus domain for a given accented constituent or, vice versa, to derive the placement of the sentence accent (nuclear accent) for a given focus domain, readjusting prominence relations accordingly.

Since we are not concerned with issues of information structure in this paper, we can abstract away from the extra complications for a prominence-based approach brought in by the notions of focus and givenness. The interested reader is referred to Büring (2002) who proposes that focus projection rules can be dispensed with in a system in which (metrical) prominence relations are taken into account and to Nespor et al. (2008), who show that the type of accent that this assigned to a phonological phrase 
depends on its metrical structure, clearly indicating that prominence is on the base of accent and not the other way round.

\subsection{Background Information}

The prosodic representation of a sentence in most formal accounts distinguishes two levels of prominence above word stress, as illustrated in (8).

(8)

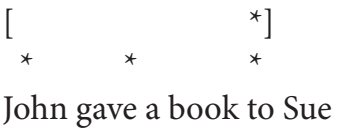

The lower level represents phrasal stress, called accent in Gussenhoven (1983, 1992) and Selkirk $(1984,1995)$. Prominence at the lower level is indicated by a grid mark in the prosodic structure. It is assigned relative to the syntactic structure (see Section 3.2 below) and it entails the assignment of an obligatory pitch accent. This level of prosodic structure is identified with the level of the phonological phrase in the prosodic hierarchy of Selkirk (1984), as illustrated in (9) (cf. Nespor \& Vogel 1986, Selkirk 1995).

(9) syllable $<$ foot $<$ prosodic word $<$ phonological phrase $<$ intonation phrase

Hence, the higher level in (8) is that of the intonation phrase, which in most cases corresponds to the sentence. The strongest stress of the intonation phrase, indicated by a second grid mark in (8), is usually referred to as sentence stress or nuclear stress (cf. Chomsky and Halle 1968) and is assigned to the most prominent constituent in the clause.

Furthermore, prosodic structure in relation to syntactic structure is assumed to be rather flat, not allowing for recursion of prosodic constituents. This is expressed in the so-called Strict Layer Hypothesis (SLH), which demands that prosodic constituents on a certain layer are all of the same type (cf. Selkirk 1984).

\subsection{Prosodic domain formation in a phase-based approach}

In this section, I will outline how prosodic constituents and the prominence relations among them are to be derived from syntactic structure. The core ingredient of the account is a two-step process in which first an initial prosodic phrasing is derived on the basis of the syntactic structure and its metrical evaluation in the interface. In a second step, this prosodic structure is adjusted according to the SLH in phonology proper, as we will discuss in detail below.

There are two basic approaches to deriving prosodic structure from syntactic structure: end-based approaches (cf. Selkirk 1984) and relation-based approaches (cf. Nespor \& Vogel 1986, Wagner 2005). End-based approaches match boundaries 
of syntactic constituents with prosodic boundaries. These alignment rules are best expressed in an OT-like account (cf. Truckenbrodt 1999).

In relation-based approaches, on the other hand, prosodic constituents are built around lexical heads on the basis of the relations they entertain with adjacent constituents. The two approaches differ in the assumption of how much syntactic information is available in the interface. While end-based approaches only assume the visibility of syntactic boundaries, relation-based ones assume the visibility of syntactic relations expressed in the X'-Schema.

In the following, I will adopt a relation-based approach, assuming that prosodic domain formation goes in parallel with the syntactic derivation in a phase-based way. The following basic facts in the mapping between syntactic and prosodic structure in German and English have to be accounted for.

First, note the differences in phrasing between a verb and an adjacent argument or adjunct (cf. Gussenhoven 1983, Krifka 1984) in German. While verb and argument obligatorily form a joint phonological phrase, a verb and an adjacent adjunct are regularly mapped onto two separate phonological phrases, as is illustrated in (10). Here and below, main stress is indicated by underlining the respective prosodic word; phonological phrases are indicated by round brackets and the intonation phrase is indicated by square brackets.
a. [ (weil Hans) (im Zelt blieb) ] since John in the tent remained
b. [ (weil Hans) (im Zelt) ( since John in the tent smoked

Thus, the prosodic phrasing of verb and object in German (and Dutch) crucially differs from the way they are phrased in English, where they only optionally form a joint phonological phrase, as is illustrated in (11bc).
a. [(weil Hans) (das Buch las)] since Hans the book read
b. [(since John) (read the book)]
c. $[($ since John $)($ read) (the book)]

In Hinterhölzl (2009), I propose two modes of prosodic composition which apply in a uniform way in German and English and take into account the phase status of syntactic constituents: while constituents that belong to the same phase-predicate (a predicate and its arguments) are mapped onto a joint phonological phrase (prosodic subordination), constituents that belong to different phase-predicates (a verb or noun and its adjuncts) are mapped onto separate phonological phrases, as is illustrated in (12). (12) accounts for the data in (10). We will come back to the contrast in (11) in Section 3.4 below. 
(12) Modes of prosodic composition (Hinterhölzl 2009)

a. subordination: $(\mathrm{DP})+\mathrm{V} \rightarrow((\mathrm{DP}) \mathrm{V})$

b. coordination: (PP) \& V -> (PP) (V) (where PP is an adjunct

\subsection{Syntactic structure and default prominence}

After the mapping of prosodic phrases from syntactic phrases, the heads of these prosodic constituents have to determined as the most prominent element within it, raising the question of what default prominence is derived from. A straightforward answer to this question comes from a simple metrical evaluation of a binary branching syntactic tree, in which the right branch is interpreted as metrically strong. This procedure yields the correct default prominence pattern of an English sentence, as is illustrated in (13).

(13) Yesterday John visited his mother

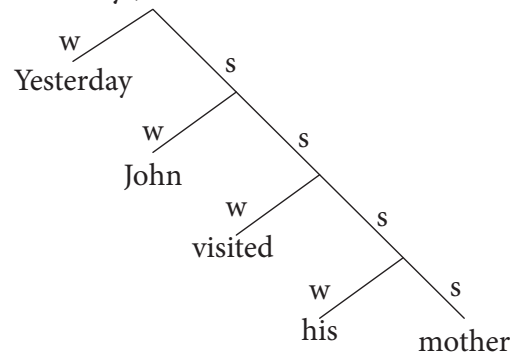

Next to the default procedure called extrinsic heading in (14a) which reflects the branching nature of a binary asymmetric syntactic tree, we need to assume a procedure called intrinsic heading in (14b), which is sensitive to the nature of prosodic constituents being combined and accounts for the assignment of main stress to the object rather than to the verb in German.

a. Extrinsic heading (default)

In prosodic composition, the right-hand member is metrically stronger than its sister constituent

b. Intrinsic heading: (language particular)

In the combination of two distinct prosodic constituents, the constituent that is higher on the hierarchical layer counts as metrically stronger than its sister constituent

I propose that languages may differ in whether they only allow for extrinsic heading or also admit for intrinsic heading. Intrinsic heading makes use of phase-theory. When the combination of a verb and its complement is evaluated prosodically, there is an intrinsic asymmetry: the DP-argument constituting a complete phase has already been mapped onto a phonological phrase when combined with the verb, which is standardly mapped onto a prosodic word. 
If we assume along the lines of Halle \& Vergnaud (1987) that during prosodic evaluation the labelled tree is converted into a bracketed grid representation, the relative strengths of the several accents in the clause and the position of the main accent are derived, as is illustrated in (15) for a putative German sentence comprising a subject DP, two adjunct XPs and a direct object DP and the verb.

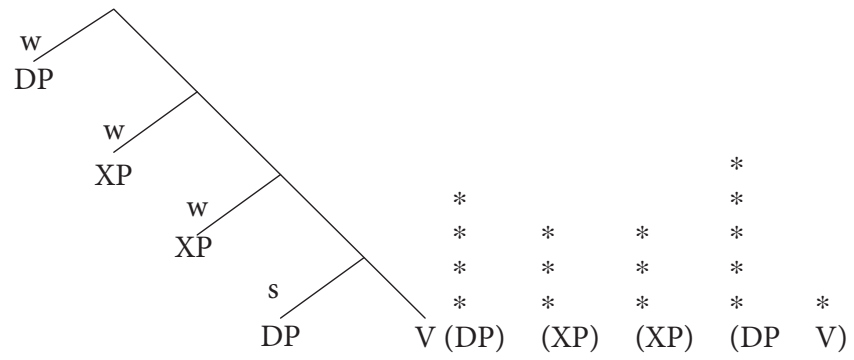

\subsection{Further operations in phonology proper}

Note that the operation of subordination creates recursive prosodic structures that violate the SLH (Selkirk 1984, Nespor \& Vogel 1986). However, Ladd (1986), Selkirk (1995), Peperkamp (1997) and Truckenbrodt (1999) provide arguments for the availability of recursive prosodic structures in certain languages.

Here, I propose that syntax derives an initial recursive prosodic phrasing which at a later level may be flattened by language specific rules that delete outer boundaries in a cyclic fashion according to global prosodic parameters like rhythm, length and branchingness of constituents and the like. In addition, I follow Nespor \& Vogel (1986), who propose the operation of restructuring to account for flexible prosodic phrasing in Italian and French. As is illustrated in (16), they argue that verb and complement are standardly mapped onto separate phonological phrases, but the object may optionally restructure with the verb, if it is non-branching.

$$
\begin{aligned}
& \text { a. (Gianni) (ha mangiato) (una mela) } \\
& \text { b. (Gianni) (ha mangiato mele) } \\
& \text { John has eaten an apple / apples }
\end{aligned}
$$

Under the assumption that non-branching prosoic constituents delete redundant prosodic boundaries, as is illustrated in (17a), I propose the following condition for the operation of restructuring in (17b).

$$
\begin{aligned}
& \text { a. } \quad(\phi(\operatorname{pwd} \mathrm{N})) \rightarrow(\operatorname{pwd} \mathrm{N}) \\
& \text { b. Restructuring: }
\end{aligned}
$$

an un-phrased prosodic constituent restructures with an adjacent phonological phrase crossing maximally one prosodic boundary.

With these assumptions in place, we are now in a position to derive the differences in prosodic phrasing between German and English and to spell out the rules that 
derive a flat prosodic structure obeying the SLH from the initial prosodic structure mapped from syntactic structure.

Remember that outer boundaries can be deleted in a cyclic fashion. After the deletion of an outer boundary an un-phrased category must either be rephrased according to the prosodic category of its prosodic sister (to respect the SLH) or undergo restructuring. From these rules and the principle in (18) which records the various faithfulness constraints between input and output in segmental phonology, it now follows that the verb must obligatorily restructure with the preceding object in German, as is illustrated in (19).

(18) preservation of (main) prominence: The deletion of prosodic boundaries must not alter pre-established prominence relations
a. weil Hans der Maria ein Buch gab
since Hans to-the Maria a book gave
b. (weil Hans) ((der Maria) ((ein Buch) gab))
c. (weil Hans) (der Maria) ((ein Buch) gab)
initial phrasing
d. (weil Hans) (der Maria) (ein Buch) gab
e. (weil Hans) (der Maria) (ein Buch $\varangle \sqrt{\text { ) gab }}$
f. (weil Hans) (der Maria) (ein Buch) (gab)
boundary deletion
boundary deletion
restructuring
rephrasing of pwd

(19b) displays the initial prosodic phrasing in a sentence in which the subject constitutes a topic: the verb forms a joint phonological phrase with the indirect and direct object, which have been mapped onto phonological phrases in the previous phase. (19c) and (19d) show the resultant structure after the respective deletion of the outermost prosodic boundary. The second step results in a representation in which the prosodic word of the verb is not part of any phonological phrase, violating the SLH. In (19e), the un-phrased verb undergoes restructuring into the adjacent phonological phrase of the preceding object crossing one prosodic boundary. Note now that the alternative option of rephrasing the verb in a separate phonological phrase is ungrammatical since the phrasing does not preserve main stress on the direct object. Since only extrinsic heading is possible in the prosodic structure in (19f), main stress would be assigned to the verb, violating the faithfulness constraint in (18).

Note that no such effect occurs in the order VO: independently of the phrasing, the main stress remains on the object, as is illustrated in (20). Thus in the order VO, languages are free to employ either the restructuring option or the rephrasing option and may impose special conditions on both options as we have seen above is the case for Italian.
a. (John) (read (a book))
b. (John) read (a book) deletion of outer boundary
c. (John) (read a book) restructuring
d. (John) (read) (a book) rephrasing 


\section{The HFF as a metrical condition}

The metrical evaluation of a binary branching, anti-symmetric tree which assigns the metrical label strong (s) to the right branch at each level, immediately makes clear why something like the weight condition should apply to adjuncts to the left and why the effect is dismissed if the adjunct appears to the right of modified head, as is illustrated again in (21).

(21) Yesterday John visited his mother

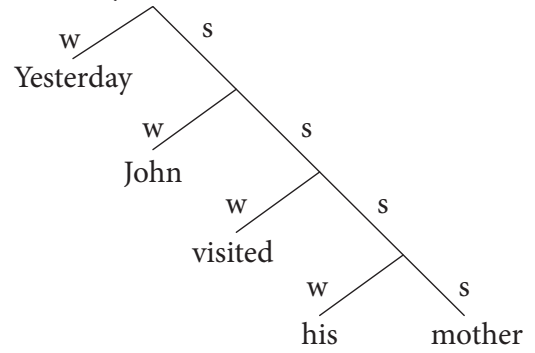

If we assume that the prosodic composition, like the syntactic derivation, starts with the head of the extended projection, that is, the verb in the sentence domain and the noun in the nominal domain, then it follows that syntactic constituents preceding this head are mapped onto a weak branch and syntactic constituents following this head are mapped onto a strong branch by default. These considerations suggest the relevance of a condition like (22).

(22) Weight-sensitivity:

A heavy syntactic phrase contained in a weight-sensitive domain must occupy a strong branch in prosodic structure

The condition in (22) raises the question of when a syntactic phrase counts as heavy in prosodic structure. In Hinterhölzl (2009b, 2013), I proposed that weight effects in the phrasal domain should be analyzed like weight effects at the word level, referring to the parallelism between X'-structure and syllable structure. At the level of a prosodic word, a syllable counts as heavy if it is bimoraic, that is, if its rhyme is branching, as is illustrated in (23), suggesting the definition of heaviness in (24).

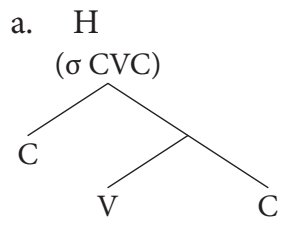

b. $\mathrm{H}$

( $\varphi$ ( $\omega_{1}$ proud $)\left(\omega_{2}\right.$ of his mother $\left.)\right)$

metrical evaluation

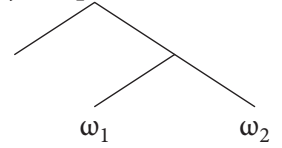

string level

(24) A syntactic phrase XP counts as heavy if both its head X and the complement of X contain lexical material 
One might think that a prosodic condition on heaviness should be a condition that applies to prosodic constituents. Note that what we are left with after the mapping of syntactic structure onto prosodic structure is a string of segments, possibly bracketed in terms of prosodic words, feet and syllables, as is illustrated in (23b). However, when we decide whether a syllable counts as heavy or not we refer to the structural level and check whether its rhyme is branching. In a similar vein, I would like to propose that when we decide whether a phonological phrase counts as heavy or not we make reference to its structural representation, that is, the arrangement of its parts in syntactic structure.

Therefore, I propose that the complex condition in (1) is broken down into two conditions. (25) applies in the interface at the point where the syntactic structure is metrically evaluated and mapped onto prosodic structure. At this point of the derivation, we may assume that syntactic constituents and their phase status are still visible. The condition in (26) may then be taken to apply in phonology proper where it accounts in a uniform fashion for heavy constituents at the level of prosodic words and prosodic phrases.

(25) A phonological phrase that corresponds to a heavy syntactic phrase in a weight-sensitive phase is assigned the metrical value $\mathrm{H}$

(26) A prosodic constituent assigned the metrical value $\mathrm{H}$ must be mapped onto a strong branch in prosodic structure

\section{The HFF as a morphological condition}

In this section, I discuss in more detail HF-effects in the nominal domain in German and English and argue that they are caused by two different types of conditions. While HF-effects in English nominals can be undone by the postposition of the adjunct remember that the adjunct in post-nominal position necessarily occupies a strong position in the metrical tree - pointing to its prosodic nature, HF-effects in German noun phrases display a phenomenon of displacement of morphology, pointing to its morphological nature.

It is tempting to relate the contrast between (27ab) and (27bc) to an adjacency condition that applies in morphological form (MF) in the framework of distributed morphology (Halle \& Marantz 1993). In (27), a HF-effect appears in prenominal position where the adjective is inflected but is absent in post-nominal position where the adjective is uninflected.
a. der [auf seine Mutter stolze] Mann
the of his mother pround man
b. *der [stolze auf seine Mutter] Mann the proud of his mother man 


\section{c. der Mann [stolz auf seine Mutter] \\ the man proud of his mother}

If we assume that inflected words are formed in the syntax and that the adjectival inflection constitutes a phrasal affix, the contrast between (27ab) follows: Given that an Agreement projection hosting the adjectival affix dominates the AP and attracts it into its specifier, we may assume that affix and head may be joined at MF under the condition of strict adjacency. This is the case in (27a) where the complement of the adjective precedes its head, but ruled out in (27b) where the complement intervenes between affix and adjectival head.

While this account may be appropriate for German (below we will see some direct evidence for this analysis), it is not clear how to extend this approach to the nominal domain in English and to the adverbial domain in German and English. For the nominal domain in English, we would have to assume that prenominal adjectives have a zero-morpheme, while post-verbal ones are uninflected, as their German counterparts, and for the adverbial domain, we would have to assume that English adverbials contain a zero-morpheme of some sort, while German adverbials do not contain such a morpheme. So to extend the morphological account of HF-effects to the nominal and adverbial domain in English, we would have to assume a number of stipulations that make this approach considerably implausible.

That HF-effects in the nominal domain in English may call for a metrical rather than a morphological account is suggested by parallel effects in Italian, which, however, cannot be explained with a morphological adjacency condition. There is a class of attributive adjectives in Italian that may appear in pre- or post-nominal position. The crucial point is that these adjectives show inflection in both positions, but a HF-effect is obsoleted by the post-nominal placement of the inflected adjective, as is illustrated in (28). This clearly speaks in favor of the relevance of a metrical condition rather than for a morphological condition.
a. un simpatico raggazzo
a pleasant boy
b. *un [simpatico per tutti] raggazzo
an pleasant to everyone boy
c. un raggazzo simpatico per tutti
a boy pleasant to everyone

Now, it is interesting to see that the evidence goes into the other direction for HF-effects in the nominal domain in German, as is illustrated in (29). ${ }^{2}$ If an adjective in German is modified by an adverbial like genug, which appears after the adjective, as is illustrated

2. The example is due to Henk van Riemsdijk whom I hereby thank for relevant discussion of the issue. 
in (29a), a HF-effect appears in its use as a prenominal modifier, as in (29b) (cf. Haider 2011). This follows straightforwardly under the analysis of the adjectival inflection as a phrasal affix (due to the lack of adjacency between the adjective and the ending), but comes as a surprise when viewed as due to the violation of the weight-condition, since it is not clear why the phrase big enough should count as heavy. Note furthermore the grammatical status of the alternatives of (29b). (29c), in which the adjectives remains without adjectival inflection is strictly ungrammatical as well, but (29d) in which the adjectival ending is attached to the adjacent adverb is acceptable for many speakers.

(29) a. Das Problem ist groß genug the problem is big enough

b. *ein großes genug Problem a big enough problem

c. *ein groß genug Problem

d. ? ein groß genuges Problem

Contributing evidence for this analysis of the German facts in (29) comes from a similar contrast in Dutch. As is discussed in detail in van Riemsdijk (1998), adjectival inflection in Dutch - though minimal, consisting in -e with non-neutral nominals and in the lack of an ending with neutral nominals - gives raise to a similar adjacency and repair effect, as is illustrated in (30).
a. een zo snel mogelijk vliegtuig (neuter) a as fast (as) possible airplane
b. *een zo snelle mogelijk auto (non-neuter)
c. een zo snel mogelijke auto
d. *een zo snel mogelik auto

In (30a), where the modified nominal is neuter the adjective snel remains uninflected and no HF-effect appears. In (30b), where the modified nominal is neuter, the adjective snel should appear with the ending -e, but the construction is ungrammatical due to lack of adjacency between the respective adjective and the noun. (30c), in which the adjectival ending attaches to the adjacent adjective mogelijk is grammatical. van Riemsdijk (1998) explains this contrast with an adjacency condition on head movement on part of the adjective.

What is relevant for us here is that the contrast between (30a) and (30b) cannot be explained in terms of heaviness, since the constituent zo snel(le) mogelijk should count as heavy or non-heavy in both cases alike. The only explanation remaining is that the observed HF-effect is morphological in nature.

The parallel effect in (29d) in German and in (30c) in Dutch is reminiscent of the displacement of morphology with participles and to-infinitives in German verb clusters, illustrated in (31). 

a. ${ }^{\star}$ ohne das Buch lesen wollen $\mathrm{zu}$ haben without the book read want-IPP to have
b. ohne das Buch haben lesen $\mathrm{zu}$ wollen without the book have read to want "without having wanted to read the book"

In (31), the infinitival prefix $z u$ should appear with the auxiliary but is attached to the lower infinitive of the modal verb instead. The reason is that the verb cluster comprising an IPP-infinitive is always right-branching, giving rise to the cluster haben lesen wollen before the infinitival marker $z u$ is applied. The infinitival marker, occupying an Aspect head in the v-domain, will attract this cluster to its specifier and will consequently be attached as a prefix to the adjacent infinitive of the modal, despite the fact that the modal is selected by the auxiliary and not by the infinitival marker.

Morphological HF-effects in the $\mathrm{v}$-domain are responsible for the phenomenon of IPP (infinitivo pro participium) in German, as is argued in detail in Hinterhölzl (2009a). Morphological adjacency effects in the v-domain are quite common in Germanic languages and appear in various forms due to different repair operations in the interface. In older German, the effect appears in its purest form as a simple displacement of the participial ending of V2 onto V3: Behaghel (1924: 367ff) notes that the construction haben + infinitive + participle occurs rather frequently in legal writings in the late 13 th and early 14 th century. The same construction, however, can already be found in the Nibelungenlied, as is illustrated in (32a). The syntactic structure giving rise to this effect is illustrated in (32c), with $\mathrm{Asp}^{0}$ hosting the participial morphology.

(32) a. ob in diu edele frouwe het lazen das getan (Nib. 634,2)

whether the royal woman had let-IN that done

b. do si so reht wol von irem allerlibsten liep het hören gerett when she so right well from her belovest lover had hear said

c. [[V2 V3] $\left.\mathrm{Asp}^{0}\right]$

A frequent variant of the above construction which is due to copying of the relevant features onto a higher head in the v-domain of the selecting verb as a last resort operation is the double participle construction (cf. Hinterhölzl 2009a). While double participle constructions are rather rare in the history of German - an example is given in (33a) they are common in colloquial variants of Frisian, Swedish and Norwegian (cf. den Dikken \& Hoekstra 1997, Wiklund 2001). (33b) illustrates the double participle in Frisian.

(33) a. hand wir unser eigen insigel geton henket (Urkunden Basel 1387) have we our own seal done hanged

b. hy soe it dien ha wollen (den Dikken and Hoekstra 1997, 1058) he would it done have wanted

The IPP-effect, that is the occurrence of a double infinitive construction, in standard German is due to a historical accident. Modal verbs in MHG lacked a participle and 
attained a new weak participle only at the beginning of the 16th century. Due to the preponderance of modal verbs in verb clusters, the use of a construction with a zeromorpheme on the selecting verb became the norm in standard German, but the situation is quite different in various modern dialects of German (cf. Höhle 2006 and Hinterhölzl 2009a for additional discussion).

To summarize this section, a HF-effect that is morphological in nature leads to a displacement of the relevant morphological ending and various repair operations in the interface. Crucially it does not necessarily give rise to an ungrammatical sentence when the relevant constituent remains in its canonical position. A HF-effect that is prosodic in nature, on the other hand, will lead to syntactic displacement of a heavy constituent into a post-verbal or post-nominal position where the effect is discarded. A heavy constituent remaining in its canonical position gives rise to an ungrammatical sentence.

In the following section, I will use these diagnostics - morphological displacement and eventual repair vs. syntactic displacement - for investigating (further) restrictions on word order in verb clusters in German and argue that this type of HF-effects in the $\mathrm{v}$-domain in German, as well as the obligatory extraposition of CP-complements from verb clusters, are neither due to the prosodic condition in (1a) nor due to the morphological condition in (2).

\section{Additional HF-effects in the German v-domain}

There is a peculiar restriction that applies in the v-domain in German. In Standard German verb clusters are predominantly left-branching, but right-branching verb clusters are possible as long as the most deeply embedded cluster is left-branching (cf. Hinterhölzl 2006b). ${ }^{3}$ A case in question is given in (34a). However, once a rightbranching verb cluster is introduced, the verb cluster must also be right-branching at the next level up (cf. (34b) and (34c)). ${ }^{4}$

$$
\begin{aligned}
& \text { a. weil er den Text [muß [lesen können]] } \\
& \text { since he the text must read can } \\
& \text { 'since he must be able to read the text' }
\end{aligned}
$$

3. There is a lot of variation in German dialects in this domain (cf. Salzmann (2013ab).

4. Verb cluster formation is argued in Hinterhölzl (2006a) to involve XP-movement of the dependent infinitives into two different functional specifiers in the v-domain of the selecting verb for licensing purposes. Given that the selecting verb moves into the highest head position in the v-domain, left- and right-branching verb clusters are derived by spelling out the dependent infinitives in the higher or lower specifier in this account. 
b. ${ }^{\star}$ weil er den Text [[müssen [lesen können]] wird] since he the text must read can will 'since he will have to be able to read the text'

c. weil er den Text [wird [müssen [lesen können]]] since he the text will must read can

The contrast between (34b) and (34c) can be analysed as a HF-effect. The syntactic phrase [müssen [lesen können]] to the left of the selecting auxiliary wird is not head final.

Also the extraposition of CP-complements from complex verb clusters, illustrated in (35), can be analyzed as a HF-effect. (35a) shows that the selecting infinitival verb and its CP-complement must form a joint constituent, to obey the Verb-Second constraint. However, as is shown in (35b), this constituent is not licit in the base-position of the infinitival verb in the verb cluster, giving rise to obligatory extraposition of the complement clause in the standard OV-approach to German, as is illustrated in (35c).
a. [sagen dass die Erde rund ist] wird man wohl können say that the earth flat is will one well can
b. *Man wird wohl [sagen dass die Erde rund ist] können
c. Man wird wohl sagen können [dass die Erde rund ist]

The traditional account for the contrast in (35bc) is given in terms of a filter by Büring \& Hartmann (1997), requiring that "finite sentences may not be governed by V or I" (p. 28ff). Note first that a condition making use of the notion of government is not admissible in the MP. Secondly, there is wide-spread agreement that complement clauses in the middle field are marginally possible in German, disqualifying also the empirical aspect of their filter, as is illustrated in (36).
a. ? weil Hans [dass Peter kommt] nicht weiß since Hans that Peter comes not knows
b. ?* weil Hans nicht [dass Peter kommt] weiß since Hans not that Peter comes knows
c. $\quad *[$ [dass Peter kommt $]$ sagen $]$ wollte Hans nicht
d. [sagen [dass Peter kommt]] wollte Hans nicht

There is an alternative account of the data in (35) that is fully compatible with the minimalist framework. Truckenbrodt (1995) argues that extraposition constitutes phonological movement by showing that the site of the landing position is constrained by prosodic rather than by syntactic conditions. His constraint is given in (37).

(37) Let XP be a syntactic category that is canonically mapped onto the prosodic category $\pi$ upon extraposition (where $\pi$ is either the phonological phrase or the intonational phrase in the following). The extraposition from NP will take XP as far as out of a prosodic constituent of the same cateogry $\pi$.

$$
(\ldots \mathrm{XP} \ldots)_{\pi} \rightarrow\left(\ldots \mathrm{t}_{\mathrm{i}} \ldots\right)_{\pi}\left(\mathrm{XP}_{\mathrm{i}}\right)_{\pi}
$$


This condition is formulated for cases of extraposition from NPs (or DPs), but may be taken to hold also for extraposition from vP. It requires that an extraposed constituent of a particular prosodic type is placed immediately outside of the phrase (of the same prosodic type) that contains it, ruling out shorter or longer movement of the extraposed constituent.

However, (34b), (35b) and (36bc) can be ruled out in a uniform manner as violations of the HFF, while the account of Truckenbrodt must find additional explanations for the data in (34bc) and (35b). Thus, I will assume that the HFF applies in the German v-domain. The question that we have to address now is whether the effect is prosodic or morphological in nature.

Our diagnostics clearly point into the direction of a prosodic effect. First note that a HF-effect can be avoided if the right-branching verb cluster is placed after the selecting auxiliary (cf. 34bc) or if the CP-complement is extraposed from the verb cluster (cf. 35bc). If no syntactic displacement obtains the relevant structures are ungrammatical. No effect of morphological displacement and/or repair is visible. All these diagnostics speak in favour of a prosodic effect and against a morphological effect.

Note, however, that these HF-effects do not follow from the weight-condition. As an example, let us take the case of (34b). The constituent [müssen [lesen [können]] does constitute a heavy constituent according to our definition, but also occupies a strong branch in prosodic structure. As a matter of fact, main stress in the complex verb cluster in (34b) falls on the verb lesen contained in the heavy constituent preceding the auxiliary wird.

This follows from the basic rules of prosodic composition argued for in Section 3.2 above. Since in (34b) a phonological phrase (comprising the cluster müssen lesen können) is combined with the prosodic word of the auxiliary wird, the heavy cluster müssen lesen können will be mapped onto a strong branch due to the rule of intrinsic heading in (14b) above. Thus the weight condition is fullfilled.

Note, however, that (34b) is ungrammatical for a much more basic reason: its initial prosodic structure cannot be mapped onto a valid output structure in phonology. ${ }^{5}$ To see this let us consider the prosodic structure of (34b) as initially derived from its syntactic structure, as is illustrated in (38).

$$
\begin{array}{ll}
\text { a. } & \text { ((müssen ((lesen) können) ) wird) } \\
\text { b. } & \text { (müssen ((lesen) können) }) \text { wird } \\
\text { c. } & \text { (müssen ((lesen) können) }) \text { wird } \\
\text { d. } & \text { (müssen ((lesen) können)) (wird) }
\end{array}
$$

restructuring is blocked stress should fall on wird

5. I thank Martin Prinzhorn, Katharina Hartmann and the audience of my talk The Head Final Filter in the syntax-prosody interface at the Wiener Sprachgesellschaft (17.6.2014) for relevant discussion of this issue. 
Assuming that each $\mathrm{vP}$ is mapped onto a phonological phrase per default we arrive at the recursive prosodic phrasing in (38a). This structure needs to be flattened by boundary deletion and re-phrasing or restructuring operations. Cyclic deletion of the outer boundaries gives rise to the representation in (38b) with an un-phrased auxiliary. The prosodic word of the auxiliary must either be re-bracketed or restructure into the adjacent phonological phrase, if possible. Note now that restructuring is impossible since the auxiliary would need to cross more than one prosodic boundary, as is illustrated in (38c). Note also that re-phrasing of the auxiliary as a separate phonological phrase does not preserve main stress, since the rule of extrinsic phrasing would assign the main accent to the auxiliary in (38d). Since in the initial mapping main stress falls on the constituent preceding the auxiliary, the condition on the preservation on prominence in (18) above is violated. Thus the syntactic structure of the verb cluster in (34b) gives rise to a crash in the syntax - prosody interface and is ungrammatical. Let us refer to this effect informally as the phrasing condition.

Why does it help also in this case to move the right-branching constituent to a position following the auxiliary (cf. 34c)? As is shown in (39), in this position, the auxiliary may either restructure into the adjacent phonological phrase crossing only one prosodic boundary (39c) or be re-phrased as in (39d), since re-phrasing in this case does not lead to a change in pre-existing prominence relations. The preferred option here is restructuring since it leads to two phonological phrases of equal size, as is indicated in (39e).
a. (wird (müssen ((lesen) können)))
b. wird (müssen ((lesen) können))
c. (wird müssen) ((lesen) können)
d. (wird) (müssen ((lesen) können))
e. (wird müssen) (lesen können)
restructuring
rephrasing

In essence, what I am proposing here is that HF-effects in the $\mathrm{v}$-domain arise from an initial recursive prosodic phrasing derived from syntactic structure that needs to be rephrased to obtain the flat prosodic structure required by the SLH. As we have seen above, a right-branching verb cluster on a left branch cannot be rephrased to a form a valid prosodic output structure.

The prosodic rule of extraposition proposed by Truckenbrodt (1995) can now be interpreted as direct evidence for the prosodic nature of this effect in the German $\mathrm{v}$-domain. Note that the result of the rule in (37) is to render a prosodic structure in which prosodic sisters are of the same type obeying SLH: in the resultant structure the prosodic constituents are either two phonological phrases or two intonation phrases. I will leave open the question if this is achieved via prosodic movement as proposed by Truckenbrodt or via the spell-out of a lower copy as proposed in Hinterhölzl (2009). In the following section, I want to discuss how the present approach squares with the much-debated FOFC-condition. 


\section{HF-Effects and the FOFC}

In recent years, a new syntactic condition has been proposed that accounts for the pattern in (34). ${ }^{6}$ The condition is termed the Final-over-Final constraint and has been proposed, discussed and refined in various publications by Biberauer, Holmberg \& Roberts (2007, 2014, to appear). An initial version is given in (40).

(40) The Final over Final Constraint (FOFC):

If $\alpha$ is a head-initial phrase immediately dominated by $\beta$, then $\beta$ must be head-initial as well; if $\alpha$ is a head-final phrase, $\beta$ may be head-initial or head-final.

The condition was originally motivated to account for a well-known fact in the history of English. In Old English, we find OV and VO orders as well as Aux V and V Aux orders, but the combination VO Aux is not found. Hence Biberauer, Holmberg and Roberts argue that the missing pattern is excluded by the syntactic constraint in (40).

The problem with a syntactic condition of this type is twofold. First, one would expect it to apply across the board. Second, one would like to know why a condition like (40) should hold at all. As for the first issue, Biberauer, Holmberg and Roberts argue that it is a general condition that applies in all sentence domains and in all languages. There are two major exceptions to a general syntactic rule like (40).

A. DPs and PPs in OV-languages, which give rise to a right-branching constituent that itself occupies a left branch with respect to the verb: ((D/P NP/DP) V)

B. Sentence final particles (SFPs) in many languages, including Mandarin Chinese (Paul 2014), as is illustrated in (41).
a. [[Wǒ zuótiān dào Zhāng jiā chī fàn] le] 1SG yesterday go Zhang home eat food PART
'I went to the Zhangs for dinner yesterday'.
b. [[Tā huì shuō zhongwén ] ma ] 3 Sg can speak Chinese Part
'Can he speak Chinese?'
c. [[Nĩ yĕ yào qù $]$ a $]$
2Sg also want go Part
'You also want to go!'

6. An alternative syntactic condition to the HFF was already proposed in Haider (1997). Moreover, Haider (2013, p. 132-135) shows that the FOFC follows from his Binary Branching Condition (BBC). 
Paul (2014) convincingly argues that SFPs in Chinese constitute functional heads in the C-domain that can be distinguished in three classes: a lower class, including the particle le in (41a), which interact with the tense/aspect system; a class of force related particles including the element $m a$ in (41b) that serve for clause typing with $m a$ indicating interrogative force and a class of high particles like $a$ in (41c) that indicate various types of speaker attitudes with $a$ signaling the speaker's surprise about the state of affairs expressed by the complement IP/TP.

C. Complex Pre- and postpositional phrases in Chinese and German, as discussed in Djamouri, Paul and Withman (2013) with some German cases illustrated in (42).
a. [[unter der Brücke] durch] under the bridge through
b. [[von morgen] an]
from tomorrow on

As for the cases of type A), Biberauer, Holmberg and Roberts (2010) propose a refinement of the original condition, as given in (43).

(43) FOFC (informal statement)

A head-final phrase $\alpha$ P cannot dominate a head-initial phrase $\beta$ P, where $\alpha$ and $\beta$ are heads in the same extended projection.

According to (43), no violation of the FOFC constraint arises in cases like A) since the verb and the determiner or the preposition are not part of the same extended projection. This account is tentatively extended to the cases in B) under the assumption that particles lack a syntactic category and thus do not belong to the extended projection of any head.

Let us now turn to its motivation and the question of why a condition like (40/43) should hold at all. They propose that FOFC is an effect of the distribution of a movement- triggering feature in extended projections that is subject to relativized minimality.

To see what they mean, let us reconsider the ungrammatical order ${ }^{\star} \mathrm{V}$ O Aux: to derive this order in an anti-symmetric framework, one would have to assume that $\mathrm{v}$ does not have the movement triggering feature for attracting the object to its specifier, while a Tense or Aspect projection hosting the auxiliary would be marked for the movement triggering feature attracting VP across the intervening $\mathrm{v}$ head that does not carry a movement triggering feature, violating relativized minimality.

Thus FOFC is definitely much better motivated than the original syntactic HFF. But let us see now, how our interface approach fares with violations of and exceptions to FOFC. Note first that the pattern ${ }^{\star} \mathrm{V}$ O Aux gives rise to the same prosodic structure as the ungrammatical verb cluster in (34b) above, as is illustrated in (44). 
(44) a. $\quad{ }^{*} \mathrm{~V}$ O Aux

b. ((V (DP)) Aux) initial prosodic structure

c. (V (DP)) Aux deletion of outer boundary

As above, the initial prosodic structure cannot be mapped onto a correct prosodic structure obeying the SLH, since restructuring is impossible and re-bracketing leads to a change in main prominence.

Let us now address the question of how the interface approach would deal with the three exceptions discussed above. First, I would like to discuss why DPs and PPs in OV-languages do not give rise to the phrasing problem illustrated in (44). Here the crucial difference seems to be that DPs (and CPs) can be taken to constitute complete phases. I propose that a DP can be evaluated in the phase in which its formal features, including case, have been checked. For the sake of the argument, I will assume that this is the T-domain for structural case and the P-domain for oblique case. In the example in (19) above, we were only considering a simple DP containing a determiner and a noun. Let us see why also more complex DPs do not give rise to a crash in the phonological component. In (45) below, I will only focus on the phrasing of the object and the verb in final position. The account rests on the well-accepted assumption that mapping onto the interfaces applies in a phase-based fashion.
a. Er hat [den Freund meiner Schwester] getroffen He has the friend of my sister met
b. (den (Freund (meiner Schwester))) initial phrasing of the object
c. (den Freund) (meiner Schwester) structure after evaluation
d. ((den Freund) (meiner Schwester) getroffen) $\quad \mathrm{DP}+\mathrm{V}$

(44b) displays the initial phrasing of the object. Since this object constitutes a complete phase and occupies the T-domain in an antisymmetric approach to the syntax of OVlanguages (cf. Kayne 1994), the latter can be prosodically evaluated and is mapped onto a flat prosodic structure respecting the SLH, as is illustrated in (44c). As is shown in (44d), combining this object with the verb leads to a phonological phrase that contains two phonological phrases and the prosodic word of the verb. The latter can then restructure into the second phonological phrase (corresponding to the DP complement of the friend ) in the usual manner.

The difference between (44) and (43) lies in the fact that the DP in (43) is still contained in the v-domain and cannot be prosodically evaluated, leading to a crash in the mapping of syntactic structure onto prosodic structure of that domain. The difference between (44) and illicit verb clusters in (34) above lies in the fact that the vPs/ Aspect-phrases contained in verb clusters do not constitute complete phases, as CPs and DPs do, and thus are not prosodically evaluated separately and can therefore only be simplified by cyclic deletion of outer boundaries and restructuring operations, as outlined above. 
What about sentence final particles? According to Chao (1968, p. 149), SFPs in Chinese "are enclitics (unstressed final syllables) which are in construction with a preceding phrase or sentence, though phonetically closely attached to the syllable immediately preceding it". ${ }^{7}$ If these particles have the prosodic status of clitics, they will not give rise to a prosodic HF-effect for the following reason. Selkirk (1995) proposes that monosyllabic function words are exempt from the SLH and argues that they constitute simple syllables, when not occurring in isolation. These syllables are then either adjoined to a prosodic word as affixal clitics, or to a phonological phrase as free clitics, as is illustrated in (46).

$$
\begin{array}{lll}
\text { a. } & \left(\Phi\left({ }_{\mathrm{pwd}} \sigma\left(_{\mathrm{pwd}} \text { lex }\right)\right)\right) & \text { affixal clitic } \\
\text { b. } & \left(\Phi \sigma\left(\Phi\left({ }_{\mathrm{pdw}} \text { lex }\right)\right)\right) & \text { free clitic }
\end{array}
$$

Let us assume for the sake of argumentation that sentence final tense/aspect particles in Mandarin Chinese are free clitics. Then their representation follows directly from the rules of prosodic composition proposed above. As is illustrated in (47), sentence final particles analyzed as free clitics can be added to a given prosodic structure without inducing any restructuring or re-phrasing operation. Assuming that the particle le as the lowest element in the C-domain selects the TP (cf. Paul 2014) containing subject, object and verb, the rule of subordination maps them onto a joint recursive phonological phrase (cf. (12a) above). No metrical adjustments are necessary to arrive at a valid prosodic output. Furthermore, main prominence will be assigned to the phonological phrase containing the verb and its arguments by the rule of intrinsic heading in (14b) above.

$$
((\mathrm{DP}) \phi(\mathrm{V} \mathrm{DP}) \phi) \sigma) \phi
$$

Djamouri, Paul \& Whitman (2013) point out cases of complex Pre- and Post-positions in Chinese and German as problematic for the FOFC. As far as I can tell, the German examples in (48) below constitute a major problem for the FOFC, because it is rather undisputable that the sequence of a Pre- and a Post-position in these examples are part of the same extended projection. In the interface account, we can again resort to the complete phase status of the relevant DP. In the examples in (47ab), the phonological phrase projected by the DP can be deleted at the point of prosodic evaluation, allowing for the postposition to restructure with the preceding PP, and resulting in a single phonological phrase containing three prosodic words, as illustrated in (48).
a. ((unter ${ }_{\text {pwd }}($ der Brücke $\left.)\right)$ durch $\left._{\text {pwd }}\right)$
initial structure
b. ((unter $\left.{ }_{\text {pwd }}\langle\text { der Brücke }\rangle_{\text {pwd }}\right)$ durch $\left._{\text {pwd }}\right)$ evaluation of DP
c. ( unter $_{\text {pwd }}(\text { der Brücke })_{\text {pwd }}$ durch $_{\text {pwd }}$ ) restructuring of PoP

7. I am indebted for this reference to Waltraud Paul, who I also would like to thank here for her help with Chinese data. 
As these examples indicate, the presence of phases is crucial for reducing the complexity in the mapping from syntactic structure onto prosodic structure. However, the different cases that we discussed only follow, if an initial recursive prosodic structure is mapped onto a flat prosodic output structure under the restrictive conditions that we have been arguing for.

To summarize, the interface approach can account for all types of HF-effects that can be explained by FOFC. In addition, it has no problems with the main exceptions to FOFC discussed in the literature. Moreover, it may be said that it has a more natural explanation for them than FOFC has. It is the complete phase status of DPs and the clitic nature of particles that makes these exceptions fall outside of the domain of HFeffects for independent reasons.

On the other hand, the syntactic account in terms of FOFC must assume that there are also interface conditions like the weight-condition and the morphological adjacency condition. The presence of weight-effects with adjuncts in the English I-domain and their absence in the parallel domain in German cannot be accounted for by FOFC. In addition, a syntactic condition like FOFC cannot explain why certain HF-effects can be repaired by morphological displacement. In the interface account, this falls out naturally. Functional affixes (like particles) do not lead to a crash in phonology. But due to their affixal nature, they impose the additional condition of being attached to a suitable host. It is this condition that leads to morphological displacement and other repair operations. If the latter are possible no grammatical violation ensues. Only if no appropriate host is available, the structure will be ungrammatical. Note that the existence of morphological HF-effects that do not lead to ungrammaticality is very problematic for a syntactic account of HF-effects.

The interface account also explains why something like the weight condition is necessary to account for HF-effects that are structurally identical to the type A)exceptions to FOFC. Weight effects arise in the combination of adjuncts and their modified heads $\mathrm{N}$ and V. Crucially, they cannot be reduced to a failure in prosodic phrasing, since adjuncts and their modified heads always map onto separate phonological phrases and thus obey the SLH from the outset.

\section{Conclusions}

What do the interface conditions in the present account have in common? The weight condition and the phrasing condition both derive from a metrically based mapping between syntactic structure and prosodic structure and thus form a natural class. All three conditions are based on the same syntactic configuration, but it is a matter of fact that the very same syntactic configuration gives rise to three different effects that vary in their appearance and their exceptions. HF-effects can thus not be explained 
by a single syntactic condition. They have a common syntactic basis, namely the configuration of a head-initial phrase under a head final phrase, which, however, leads to different consequences at the interfaces.

\section{References}

Biberauer, Theresa, Holmberg, Anders and Roberts, Ian. forthcoming. A syntactic universal and its consequences. In The Final over Final Constraint: a word-order universal and its implications for linguistic theory, Theresa Biberauer et al. (eds.), Cambridge MA, MIT Press. doi:10.1162/ling_a_00153

Biberauer, Theresa, Holmberg, Anders and Roberts, Ian. 2014. A syntactic universal and its consequences. Linguistic Inquiry 45(2), 169-225. doi:10.1162/LING_a_00153

Biberauer, Theresa, Holmberg, Anders and Roberts, Ian. 2007. Structure and linearization in disharmonic word orders. In Proceedings of the 26th West Coast Conference of Formal Linguistics, University of California. Berkeley: Cascadilla Proceedings Project.

Cinque, Guglielmo. 1999. Adverbs and functional heads. A crosslinguistic Perspective. Oxford: OUP. Chao, Yuen Ren. 1968. A Grammar of Spoken Chinese. Berkeley: University of California Press. Chomsky, Noam. 1995. Bare Phrase Structure. In Government and Binding Theory and the Minimalist Program, Gerd Webelhuth (ed.), 383-439. Cambridge, MA: Blackwell.

Chomsky, Noam. 1998. Minimalist Explorations. Ms., Cambridge MA, MIT.

Chomsky, Noam. 2001. Derivation by phase. In Ken Hale: a life in language. M. Kenstowicz (ed.), 1-52. Cambridge, MA: MIT Press.

Chomsky, Noam. 2005. On phases. Ms., Cambridge, MA: MIT.

Djamouri, Redouane, Paul, Waltraud and Withman, John. 2013. Postpositions vs Prepositions in Mandarin Chinese: The Articulation of Disharmony. In Theoretical Approaches to Disharmonic Word Orders, Theresa Biberauer and Michelle Sheehan (eds.), 74-105. Oxford: OUP. doi:10.1093/acprof:0so/9780199684359.003.0003

Emonds, Joseph. 1976. A Transformational Approach to English Syntax. New York: Academic Press.

Escribano, Juan. 2009. Head-Final Effects and the Nature of Modification. Ph.D. dissertation, Universidad de Oviedo.

Grimshaw, Jane. 1991. Extended Projections. Ms., Brandeis University.

Gussenhoven, Carlos. 1984. On the Grammar and Semantics of Sentence Accents. Dordrecht: Foris. doi: $10.1515 / 9783110859263$

Haider, Hubert. 1993. Deutsche Syntax, generative: Vorstudien zur Theorie einer projektiven Grammatik. Tübingen: Narr.

Haider, Hubert.1997. Typological implications of a directionality constraint. In Studies on Universal Grammar and Typological Variation, Artemis. Alexiadou and Tracy Hall (eds.), 17-33. New York, Amsterdam: John Benjamins. doi:10.1075/la.13.02hai

Haider, Hubert. 2000. Adverb Placement-Convergence of Structure and Licensing. Theoretical Linguistics 26, 95-134. doi:10.1515/thli.2000.26.1-2.95

Haider, Hubert. 2011. Grammatische Illusionen - Lokal wohlgeformt - global deviant. Zeitschrift für Sprachwissenschaft 30, 223-257. doi:10.1515/zfsw.2011.009

Haider, Hubert. 2013. Symmetry breaking in syntax. Cambridge: CUP. 
Haider, Hubert. 2015. Head directionality - in syntax and morphology. In Handbook of Parameters, Antonio Fàbregas, Jaume Mateu and Mike Putnam (eds.), 73-97. London: Bloomsbury Press.

Halle, Morris. and Vergnaud, Jean Roger 1987. An Essay on Stress. Cambridge: MIT Press.

Halle, Morris and Marantz, Alex. 1993. Distributed Morphology and the Pieces of Inflection. In The View from Building 20, Kenneth Hale \& Jay Keyser (eds), 111-176. Cambridge: MIT Press.

Hinterhölzl, Roland. 2006a. Scrambling, Remnant Movement and Restructuring in West Germanic. Oxford: Oxford University Press. doi:10.1093/acprof:0so/9780195308211.001.0001

Hinterhölzl, Roland. 2006b. The Phase Condition and cyclic Spell out: Evidence from VPtopicalization. In Phases of Interpretation, Mara Frascarelli (ed.), 237-259. Berlin: Mouton de Gruyter. doi:10.1515/9783110197723.4.237

Hinterhölzl, Roland. 2009a. The IPP-effect, phrasal affixes and repair strategies in the syntaxmorphology interface. Linguistische Berichte 218, 191-215.

Hinterhölzl, Roland. 2009b. A phase-based comparative approach to modification and word order in Germanic. Syntax 12: 3. doi:10.1111/j.1467-9612.2009.00129.x

Hinterhölzl, Roland. 2010. Information Structure and unmarked word order in (Older) Germanic. In Information Structure, Malte Zimmermann and Caroline Féry (eds.), 232-306. Oxford: OUP.

Kayne, Richard. 1994. The Antisymmetry of Syntax. Linguistic Inquiry Monograph 25. Cambridge, MA: MIT Press.

Kayne, Richard. 1998. Overt versus Covert Movement. Syntax 1 (2): 128-191. doi: 10.1111/1467-9612.00006

Krifka, Manfred. 1984. Fokus, Topik, syntaktische Strukur und semantische Interpretation. Universität Tübingen.

Ladd, Robert D. 1986. Intonational phrasing: The case for recursive prosodic structure. Phonology 3, 311-340. doi:10.1017/So952675700000671

Lieberman, Michael and Prince, Alan. 1977. On Stress and Linguistic Rhythm. Linguistic Inquiry $8,249-336$.

Nespor, Marina and Vogel, Irene.1986. Prosodic Phonology. Dordrecht: Foris Publications.

Nespor, Marina et al. 2008. Different Phrasal Prominence Relations in VO and OV Languages. Lingue e Linguaggio VII.2, 1-29.

Paul, Waltraud. 2014. Why particles are not particular: Sentence-final particles on Chinese as heads of a split CP. Studia Linguistica 68 (1), 77-115. doi:10.1111/stul.12020

Peperkamp, Sharon. 1997. Prosodic Words. Ph.D. dissertation, Universiteit van Amsterdam. HIL Dissertation 34. The Hague: Holland Academic Graphics.

Salzmann, Martin. 2013a. A new Argument for V-Cluster formation and a right-branching VP. Linguistic Variation 13.1, 81-132. doi:10.1075/lv.13.1.03sal

Salzmann, Martin. 2013b. Rule ordering in V-cluster formation. In Rule Interaction in Grammar, Anke Assmann \& Fabian Heck (eds.), Linguistische Arbeitsberichte 90, University of Leipzig, 65-121.

Selkirk, Elizabeth. 1984. Phonology and syntax: The Relation between Sound and Structure. Cambridge, MA: MIT Press.

Selkirk, Elizabeth. 1995. The prosodic structure of function words. In University of Massachusetts occasional papers 18: Papers in Optimality Theory, J.N. Beckman, L. Walsh Dickey and S. Urbanczyk (eds.), Amherst: GLSA, 439-469. 
Truckenbrodt, Hubert. 1999. On the Relation between Syntactic Phrases and Phonological Phrases. Linguistic Inquiry 30: 219-255. doi:10.1162/002438999554048

Uhmann, Susanne. 1991. Fokusphonologie des Deutschen. Tübingen: Niemeyer.

van Riemsdijk, Henk. 1998. Head Movement and Adjacency. Natural Language and Linguistic Theory 16, 633-678. doi:10.1023/A:1006075919357

Wagner, Michael. 2005. Asymmetries in prosodic domain formation. In Perspectives on Phases, Norvin Richards and Martha Mcginnis (eds.), MITWPL 49, 329-367. Cambridge, MA: MIT Press.

Williams, Edwin. 1982. Another argument that passive is transformational. Linguistic Inquiry 13, 203-238.

Zwart, Jan Wouter. 1993. Dutch Syntax. Unpublished doctoral Dissertation. University of Groningen. 